\title{
Erratum to: A distributed dynamic mesh model of a helical gear pair with tooth profile errors
}

WANG Qi-bin(王奇斌) ${ }^{1}$, MA Hong-bo(马洪波 $)^{1}$, KONG Xian-guang(孔宪光) ${ }^{1}$, ZHANG Yi-min(张义民) ${ }^{2}$

1. School of Electro-mechanical Engineering, Xidian University, Xi'an 710071, China;

2. School of Mechanical Engineering, Shenyang University of Chemical Technology, Shenyang 110819, China

(C) Central South University Press and Springer-Verlag GmbH Germany, part of Springer Nature 2018

Erratum to: J. Cent. South Univ. (2018) 25: 287-303

DOI: https://doi.org/10.1007/s11771-018-3737-4

The first author's affiliation was no longer in use in the original version of the article and it should be replaced as follows: School of Mechano-Electronic Engineering, Xidian University, Xi'an 710071, China.

Corresponding author: WANG Qi-bin, PhD, Lecturer; Tel: +86-29-88203115; E-mail: qbwangpap@163.com; ORCID: 0000-0003$4686-5336$

The online version of the original article can be found at https://doi.org/10.1007/s11771-018-3737-4 